Jurnal Riset Agama

Volume 1, Nomor 2 (Agustus 2021): 354-364

DOI: $10.15575 /$ jra.v1i2.14557

https://journal.uinsgd.ac.id/index.php/jra

\title{
Studi Pustaka Sistematis: Mahabah dalam Tasawuf Kontemporer Perspektif Buya Nursamad Kamba
}

\author{
Hidayatul Fikra \\ Jurusan Tasawuf Psikoterapi, Fakultas Ushuluddin, \\ UIN Sunan Gunung Djati Bandung, Indonesia \\ fikraarza2903@gmail.com
}

\begin{abstract}
Mahabah which is the peak of sufism becomes a proper study considering that contemporary life today often makes sense more than the real God. The purpose of this study is to explore how the reflection of the mahabah when viewed from the perspective of a contemporary sufi, Buya Nursamad Kamba. The research method used is descriptive-qualitative with a library research approach. The results showed that the point of view taken by Buya Nursamad Kamba in perceiving mahabah is by focusing on the concept of Muhammad's personality by elaborating and integrating the value of love for Allah in every aspect of life. The conclusion that can be drawn from the results of this study is Buya Nursamad Kamba's view of the concept of mahabah is very unique and adapts to the development of the times in this contemporary era.
\end{abstract}

Keywords: Buya Nursamad Kamba; Contemporary Sufism; Mahabah; Sufi.

\begin{abstract}
Abstrak
Mahabah yang merupakan puncak tasawuf menjadi suatu kajian yang tepat mengingat kehidupan kontemporer saat ini seringkali menuhankan akal daripada Tuhan sebenarnya. Tujuan penelitian ini adalah mengupas bagaimana refleksi mahabah jika dilihat dari perspektif seorang sufi kontemporer, Buya Nursamad Kamba. Metode penelitian yang digunakan adalah deskriptif-kualitatif dengan pendekatan library research. Hasil penelitian menunjukkan bahwa sudut pandang yang diambil Buya Nursamad Kamba dalam mempersepsikan mahabah yaitu dengan menitikberatkan pada konsep memuhammad-kan diri dengan cara peneladanan dan mengintegrasikan nilai kecintaan kepada Allah dalam setiap segi kehidupan. Kesimpulan yang dapat ditarik dari hasil penelitian ini yaitu pandangan Buya Nursamad Kamba
\end{abstract}


Jurnal Riset Agama, Volume 1, Nomor 2 (Agustus 2021): 354-364

Hidayatul Fikra/Studi Pustaka Sistematis: Mahabah dalam Tasawuf

Kontemporer Perspektif Buya Nursamad Kamba

mengenai konsep mahabah sangat unik dan menyesuaikan dengan perkembangan zaman di era kontemporer ini.

Kata kunci: Buya Nursamad Kamba; Mahabah; Sufi; Tasawuf Kontemporer.

\section{Pendahuluan}

Dunia modern menghantarkan manusia pada penghargaan berlebihan terhadap kemajuan sains dan teknologi serta lebih mengedepankan aqly (rasional) daripada athfy (emosional). Hal ini terjadi dalam berbagai sendi kehidupan dan seringkali membuat manusia merasakan kekosongan (Kumalla, 2019). Ajaran tasawuf yang pada intinya memperkenalkan mahabah atau cinta merupakan sebuah jawaban atas rasa kekosongan tersebut. Salah satu bukti hal ini adalah beralihnya fokus Imam al-Ghazali dari pengkajian filsafat yang berorientasi pada akal ke tasawuf yang lebih mengedepankan hal-hal yang bersifat rohani, karena adanya ketidakpuasan batiniyah meskipun memiliki ilmu yang mendalam tentang filsafat (Irham, 2012). Menurutnya, untuk menemukan kesenangan batiniyah hanya dapat diraih dengan kedekatan kepada Allah melalui perasaan cinta mendalam sebagai bentuk manifestasi ma'rifat kepada-Nya (Wati, 2014). Seorang sufi kontemporer yang dikenal dengan sebutan Buya Nursamad Kamba juga menjadikan mahabah sebagai topik utama dalam pemikirannya. Beberapa tulisannya bahkan mengajak para pembaca untuk mereparasi akal dan membangun kesadaran akan kecintaan Allah yang tak pernah berhenti kepada umat-Nya.

Sejumlah penelitian sebelumnya telah mengungkapkan pemikiran para sufi mengenai konsep mahabah, antara lain hasil penelitian yang ditulis oleh Hartati (2018), berjudul "Mahabah Perspektif al-Ghazali dan Rabi'ah al-Adawiyah (Studi Komparasi)," UIN Sunan Gunung Djati Bandung. Penelitian ini menggunakan konsep perbandingan pemikiran antara dua pemikiran al-Ghazali dan Rabi'ah al-Adawiyah tentang mahabah menggunakan penelitian kualitatif dengan pendekatan library research. Hasil penelitian menunjukkan bahwa al-Ghazali memiliki konsep mahabah vertikal (kepada Allah) namun dapat dimanifestasikan dalam bentuk horizontal kepada makhluk. Sedangkan Rabi'ah memiliki konsep mahabah murni, yaitu semata-mata kecintaan kepada Allah (Hartati, 2018). Selain itu, terdapat penelitian Hisnuddin (2020), berjudul "Pendidikan Cinta Kasih Perspektif Jalaludin Rumi," UIN Syarif Hidayatullah Jakarta. Penelitian ini menekankan pada teori bentuk implementasi cinta pemikiran Rumi dalam pendidikan Islam dengan penelitian kualitatif melalui analisis teks. Hasil penelitian menunjukkan 
Jurnal Riset Agama, Volume 1, Nomor 2 (Agustus 2021): 354-364

Hidayatul Fikra/Studi Pustaka Sistematis: Mahabah dalam Tasawuf

Kontemporer Perspektif Buya Nursamad Kamba

tiga pemikiran Rumi terkait mahabah, yaitu sebagai kendaraan menuju Allah, sebagai bentuk kerinduan ingin berjumpa dengan-Nya, dan terakhir untuk merasakan kefanaan, dengan mengosongkan hati dari segala keburukan dan melebur ke dalam cinta-Nya (Hisnuddin, 2020). Selanjutnya penelitian Ali Saputra (2019), "Konsep Mahabah (Cinta) dalam Pemikiran Syekh Zulfikar Ahmad," UIN Syarif Hidayatullah Jakarta. Teori yang digunakan adalah teori mahabah dalam tasawuf yang dianut oleh Syekh Zulfikar Ahmad, menggunakan metode penelitian deskriptif-kualitatif melalui telaah pustaka. Hasil penelitian mengungkapkan bahwa Syekh Zulfikar Ahmad memiliki konsep bahwa mahabah merupakan kondisi hati para pecandu rindu sangat ingin bertemu dengan-Nya dengan melaksanakan prinsip-prinsip sehingga mencapai derjat yang lebih tinggi (Saputra, 2019).

Hasil penelitian terdahulu di atas memberi kontribusi terhadap penyusunan kerangka teori dalam penelitian ini. Manusia dan alam semesta diciptakan dengan cinta dan sudah seharusnya kembali diarahkan kepada Allah dengan cinta pula (Kamba, 2018). Pendekatan terhadap Sang Pencipta melalui mahabahnya tasawuf dalam masa kontemporer seperti saat ini lebih mengarah pada pengalaman sufistik, bukan semata dengan kekayaan intelektual atau ibadah syariat saja. Hal ini jika dikupas bahkan lebih dalam maknanya daripada itu. Pengalaman sufistik yang dimaksudkan adalah dengan kecintaan kepada Allah, penghayatan akan nilai-nilai kebaikan dan ajaran-ajaran agama dapat membentuk kesadaran serta pengalaman keberagamaan, dan pada akhirnya muara semua cinta akan mengarah hanya kepada-Nya (Kamba, 2020). Semua bentuk kecintaan kepada Allah ini telah diteladankan oleh orang yang paling mulia, Baginda Rasulullah, dan dengan mengikutinya jalan kehidupan akan menjadi benar. Dalam tasawuf, salah satu jalan kehidupan tersebut dapat ditempuh dengan jalan tarekat, yaitu menaiki tingkatan-tingkatan sebagai upaya salik dalam meningkatkan derajat dan ketakwaannya. Secara keagamaan, tarekat dinilai sebagai wadah untuk menanamkan dan mentransmisi nilai-nilai keagamaan pada diri masyarakat, dan puncaknya adalah pencapaian pada tingkatan ma'rifat dan mahabah (Haryanto, 2014). Dalam pemikiran Buya Nursamad Kamba, aplikasi dari teladan Rasul dan menaiki tingkatan-tingkatan tersebut akan menjadikan seorang hamba tidak terbelenggu oleh dunia sehingga dapat mencintai Allah secara merdeka.

Berdasarkan uraian di atas, maka peneliti menyusun formula penelitian yang terdiri dari rumusan masalah yaitu Buya Nursamad Kamba sebagai seorang sufi kontemporer memiliki pemikiran dan perspektif berbeda mengenai konsep mahabah. Adapun pertanyaan penelitian terkait rumusan masalah tersebut adalah bagaimana konsep mahabah dalam tasawuf kontemporer jika dilihat dari perspektif Buya 
Jurnal Riset Agama, Volume 1, Nomor 2 (Agustus 2021): 354-364

Hidayatul Fikra/Studi Pustaka Sistematis: Mahabah dalam Tasawuf

Kontemporer Perspektif Buya Nursamad Kamba

Nursamad Kamba. Penelitian ini sejatinya bertujuan untuk mengungkapkan pandangan Buya Nursamad Kamba sebagai sufi kontemporer mengenai konsep mahabah yang telah dituangkannya ke dalam bentuk tulisan berupa buku dan jurnal. Berdasarkan tujuan tersebut, penelitian ini diharapkan mampu memberikan manfaat dalam mengembangkan khazanah pengetahuan Islam, khususnya di bidang tasawuf.

\section{Metode Penelitian}

Penelitian ini menggunakan jenis kualitatif, yaitu dengan penggambaran fakta, data dan objek material lainnya yang bukan berupa angka, melainkan berupa ungkapan bahasa dan wacana secara tepat dan sistematis (Hasnawati, 2015), dengan pendekatan library reseach (Darmalaksana, 2020), yaitu dengan mengumpulkan dokumen-dokumen yang dapat diklasifikasikan sebagai sumber data primer berupa karyakarya Buya Nursamad Kamba dan sumber data sekunder berupa tulisan atau dokumen cendikiawan lainnya yang relevan dengan penelitian. Data yang telah diklasifikasikan akan diolah dengan teknik analisis isi (content analysis) dengan memaparkan isi dari dokumen-dokumen sumber secara lebih mendalam dan terperinci secara objektif, serta mengaitkannya dengan fenomena sosial yang terjadi (Ahmad, 2018). Hasil penelitian dari berbagai literatur tersebut kemudian akan ditarik menjadi sebuah kesimpulan.

\section{Hasil dan Pembahasan}

\section{Biografi Buya Nursamad Kamba Muhammad}

Nursamad Kamba atau yang akrab dikenal dengan Buya Kamba merupakan seorang sufi kontemporer kelahiran Pinrang, Sulawesi Selatan pada tanggal 23 September 1958 (Mustofa, 2019), dan wafat di Jakarta Timur pada tanggal 20 Juni 2020 dalam usia 61 tahun (Ferry, 2020). Semasa hidupnya, beliau merupakan seorang pengajar dalam dunia pendidikan formal (pendiri sekaligus dosen jurusan Tasawuf Psikoterapi di UIN Sunan Gunung Djati Bandung), seorang marja' (rujukan keilmuan) di Maiyah, penulis buku dan jurnal serta menjadi pembicara di seminar, simposium, dan konferensi baik lokal maupun luar negeri. Namun demikian, setiap sisi kehidupan beliau tidak luput sebagai pendakwah di bidang tasawuf (Rahman, 2019).

Berbekal pendidikan Islam dari sang ayah, Abd. Samad Kamba, Buya Kamba mulai menempuh pendidikan formal layaknya anak pada umumnya. Pendidikan formal dari sekolah dasar hingga sekolah menengah atas ditempuh di Leppangang dan Pare-Pare, kemudian dilanjutkan ke Universitas Islam Addariyah. Kehausan beliau terhadap ilmu terbukti dengan studi yang dilanjutkan ke Universitas Al-Azhar, 
Jurnal Riset Agama, Volume 1, Nomor 2 (Agustus 2021): 354-364

Hidayatul Fikra/Studi Pustaka Sistematis: Mahabah dalam Tasawuf

Kontemporer Perspektif Buya Nursamad Kamba

Mesir pada jenjang pendidikan S1, S2, dan S3 di program Teologi Islam, fakultas Ushuluddin. Pasca pendidikan di Kairo, beliau kembali menimba ilmu postdoctorate di McGill University, Kanada. Perjalanan pendidikan dengan program studi Teologi Islam tersebut diwarnai oleh Tasawuf tepatnya saat beliau berada pada jenjang S2 di Universitas Al-Azhar. Pertemuan dengan seorang mursyid tarekat Naqsabandiyah di Mesir, Muhammad Dhiyauddin al-Kurdi, memberi angin segar bagi kegelisahan hati Buya Kamba saat mempelajari Teologi. Buya Kamba menilai bahwa mempelajari Teologi bukan membuatnya bertambah dalam mengenal Islam, melainkan membuat pemikirannya menjadi dangkal, disebabkan adanya pertentangan pemikiran antar sekte yang ada dalam Teologi. Sejak saat itu, beliau terus mendalami tasawuf dan mengamalkannya dalam kehidupan (Mustofa, 2019).

\section{Konsep Mahabah Perspektif Buya Nursamad Kamba}

Pada zaman tasawuf klasik dulu, seperti mahabah dalam pandangan sufi perempuan Rabi'ah al-Adawiyah, secara gamblang menyatakan kecintaan terhadap Allah harus memenuhi seluruh relung hati, bahkan tiada tempat yang tersisa untuk hanya membenci setan. Tingkatan zuhud dalam maqam tasawuf yang bersifat khauf dan raja yang dicetuskan oleh Hasan Basri, dinaikkan oleh Rabi'ah al-Adawiyah ke jenjang yang lebih tinggi, yaitu zuhud dengan sifat $h u b b$. Ini adalah bentuk kecintaan yang murni yang mana tidak menakuti hal lain selain Allah termasuk neraka yang merupakan ciptaan-Nya, dan tidak pula pada harapan untuk memasuki surga-Nya. Semua ibadah dan kebaikan yang dilakukan sejatinya karena kecintaan yang luar biasa kepada Allah (Wasalmi, 2014). Selain Rabi'ah al-Adawiyah, di zaman klasik juga ada Dzunnun al-Misri yang menjabarkan mahabah dalam empat hal, yaitu kecintaan kepada Yang Maha Agung, benci kepada yang segala yang bersifat fana, mengikuti firman Allah yang diturunkan dalam bentuk Al-Quran, dan takut akan tergelincir dalam kesesatan dan kemaksiatan (Wati, 2014).

Namun mahabah dari sudut pandang Buya Kamba disesuaikan dengan segala perkembangan pada zaman kontemporer ini. Hal ini tidak berarti konsep mahabah secara utuh jauh berbeda dengan tasawuf zaman klasik, akan tetapi beliau berhasil memodifikasi bentuk mahabah tersebut ke dalam suatu bingkisan tasawuf yang lebih menarik, sehingga tasawuf tidak lagi dinilai sebagai sesuatu yang tabu di mata masyarakat.

Konsep mahabah Buya Kamba diwarnai oleh corak pemikiran alJunaid (Kamba, 2020). Dalam pandangannya, mahabah merupakan suatu dasar esensial yang mewarnai hubungan hamba dengan Tuhan. Penciptaan makhluk yang dilandasi oleh cinta Ilahi, mengharuskan makhluk mengenali (ma'rifat) kemudian mencintai (mahabah) Tuhannya dalam setiap langkah kehidupan. Sedangkan kesenjangan yang terjadi 
Jurnal Riset Agama, Volume 1, Nomor 2 (Agustus 2021): 354-364

Hidayatul Fikra/Studi Pustaka Sistematis: Mahabah dalam Tasawuf

Kontemporer Perspektif Buya Nursamad Kamba

antara para sufi dan fuqaha adalah doktrin agama yang didominasi oleh iming-iming kenikmatan surga dan ancaman akan siksaan neraka (Kamba, 2020). Padahal misi agama pada hakikatnya bersifat transformatif. Agama dan wahyu yang diturunkan kepada Rasulullah berfungsi untuk menjemput dan mengantarkan manusia dari kegelapan menuju cahaya, dari perilaku buruk menuju perilaku baik dan dari manusia imanen (berada dalam kesadaran) menuju manusia yang transenden (luar biasa). Dan satu-satunya cara yang paling ideal untuk mewujudkan misi agama tersebut adalah dengan memiliki cinta (Fikra, Studium generale, 15 Maret 2019).

Kecintaan kepada Allah harus didahului oleh ma'rifat dikarenakan pengetahuan sebelum mencintai itu sangat penting. Semakin tahu seseorang akan sesuatu yang dicintainya, maka akan bertambah pula perasaan kepada yang dicintai tersebut. Begitu pula kepada Allah. Pengetahuan tentang-Nya tidak diketahui dengan cara memikirkan wujud-Nya, akan tetapi dengan merasakan kehadiran-Nya (Fikra, Studium generale, 15 Maret 2019). Dengan demikian akan ada sikap pengangungan dari hamba kepada Sang Khaliq, merasa malu jika berbuat kesalahan yang tidak disukai-Nya, terdorong untuk bertaqarrub kepada-Nya, dan menunaikan segala perintah-Nya demi mencapai keridaan-Nya (Kamba, 2020).

Buya Kamba mengidentifikasikan gejala pertama dalam cinta adalah menyenangi segala yang diberitakan Allah, menyukai dan meridainya. Gejala ini kemudian akan tercermin dalam kesinambungan ingatan kepada Allah yang direalisasikan dalam bentuk pengabdian kepada-Nya, membebaskan diri dari kecenderungan ego dan hawa nafsu dan berserah diri secara total kepada-Nya (Kamba, 2020). Kritik Buya Kamba terhadap orang-orang yang mengaku cinta kepada Allah dengan cara yang salah dituangkannya melalui buku "Tuhan Maha Asyik". Banyak orang mengaku cinta kepada Allah akan tetapi memonopoli agama yang pada hakikatnya adalah sesuatu yang sakral dari-Nya, menjadi tunduk atas kepentingan sebagian golongan. Padahal Tuhan adalah kebaikan yang absolut, artinya saat seorang hamba melakukan suatu kebaikan maka dia sedang bertuhan saat itu juga. Hal ini berarti bentuk ibadah bukan hanya dengan melakukan shalat atau serangkaian ibadah lainnya, namun saat berbuat baik kepada manusia ataupun makhluk lain pun juga termasuk ibadah dan salah satu upaya dalam meraih cinta-Nya (Pratiwi \& Liliani, 2021).

Mahabah pada akhirnya mendambakan sebuah pertemuan. Dalam bahasa kaum millenial, Buya Kamba menganalogikan mahabah seperti sepasang muda-mudi yang sedang kasmaran. Ada harapan dan keinginan untuk bertemu setiap saat, mengingat segala hal tentang pasangan sekecil apapun itu, bahkan hanya untuk mendengar suaranya apapun dapat 
Jurnal Riset Agama, Volume 1, Nomor 2 (Agustus 2021): 354-364

Hidayatul Fikra/Studi Pustaka Sistematis: Mahabah dalam Tasawuf

Kontemporer Perspektif Buya Nursamad Kamba

diupayakan (Fikra, Studium generale, 29 Maret 2019). Sejatinya, mahabah memiliki dua daya juang, yaitu daya juang untuk menemui Allah dan daya juang untuk mendapatkan restu-Nya. Untuk mendapatkan daya juang yang pertama, hamba harus berusaha mendapatkan restu Allah dengan cara tulus, ikhlas dan tanpa pamrih dalam mencintai-Nya. Mahabah ini kemudian akan melahirkan sifat-sifat utama pada diri seorang hamba, antara lain sifat al-itsar (altruisme), yaitu mendahulukan kepentingan orang lain daripada kepentingan diri sendiri. Sifat ini telah diteladankan oleh Nabi Muhammad semasa perjuangannya dalam menyebarkan dakwah Islam. Selain itu, beliau juga membangun sifat ini kepada para sahabat dari kaum Anshar sehingga mereka mau memudahkan urusan kaum Muhajirin yang pindah ke Madinah. Sifat yang kedua yaitu al-futuwwah (kekesatriaan), yaitu keberanian menegakkan kebenaran. Dan yang ketiga yaitu al-sakha (kedermawanan). Sikap kedermawanan ini lahir dari sifat al-itsar yang juga melahirkan istighna atau merasa cukup. Seseorang yang mencintai Allah akan merasa cukup dengan apapun yang diberikan-Nya tanpa berkeluh kesah, bahkan jika menemukan orang lain yang lebih membutuhkan daripada dirinya, ia akan mendermakan miliknya (Kamba, 2020).

\section{Refleksi Mahabbah Tasawuf Kontemporer Buya Nursamad Kamba}

Buya Kamba menegaskan bahwa bentuk mahabah kepada Allah yang tertinggi adalah dengan cara me-muhammad-kan diri. Nabi Muhammad sebagai manusia paling mulia di muka bumi telah disertai dengan akhlak paling indah yang tiada satupun dapat menandinginya. Beliau adalah kekasih Allah yang namanya bahkan diagungkan di langit dan di bumi. Peneladanan terhadap akhlak dan kepatuhan terhadap ajaran yang disampaikannya merupakan hal utama yang semestrinya dilakukan oleh seorang hamba-Nya. Mahabah tidak semata melalui lisan, namun dipraktikkan dalam setiap gerak-gerik kehidupan sehari-hari (Kamba, 2018).

Kehidupan yang dimulai dengan bangun tidur di pagi hari, dalam keteladanan yang diberikan Rasulullah, manusia diajarkan untuk segera berzikir dalam bentuk doa bangun tidur. Dalam konsep mahabah, doa yang dibaca saat bangun tidur bukan sebatas bersyukur karena telah dihidupkan kembali oleh Allah, akan tetapi memiliki makna yang jauh lebih dalam daripada itu. Semangat menjalani kehidupan di hari yang baru dilakukan dengan penuh apresiasi sehingga dapat menghubungkan hamba dengan Allah. Ini merupakan makna tersirat dari doa bangun tidur. Arti dari doa bangun tidur yaitu "segala puji bagi Allah yang telah menghidupkan kami setelah kami mati dan hanya kepada-Nya kami kembali" adalah bentuk pengagungan kepada Tuhan sebagai pemilik ruh karena tidak ada satupun yang dapat mematikan dan menghidupkan 
Jurnal Riset Agama, Volume 1, Nomor 2 (Agustus 2021): 354-364

Hidayatul Fikra/Studi Pustaka Sistematis: Mahabah dalam Tasawuf

Kontemporer Perspektif Buya Nursamad Kamba

kecuali Dia dan atas kehendak-Nya. Kembali kepada Allah menyiratkan bahwa bukan jiwa dan raga saja yang kembali kepada-Nya setelah manusia meninggal, akan tetapi saat hidup di dunia jiwa tersebut haruslah terpanggil menuju Allah dengan selalu mengharap cinta dan kasih-Nya. Setiap aktivitas baik berupa ibadah maupun muamalah dengan sesama manusia ditujukan agar diri semakin dekat dengan yang dicintai.

Contoh lainnya dapat dilihat pada panggilan muazzin untuk menunaikan ibadah salat. Seorang yang mencintai Allah tidak akan menunggu hingga muazzin menyelesaikan azannya, akan tetapi bersegera memenuhi panggilan tersebut. Upaya menyucikan diri dengan berwudu membersihkan anggota tubuh sebelum menunaikan ibadah salat adalah bentuk persiapan menemui Zat yang dicintai. Ibadah yang dilakukan tidak lagi dipandang sebagai tuntutan apalagi sebagai beban, namun menjadi sebuah kebutuhan dan kesenangan. Dalam hadis yang diriwayatkan oleh an-Nasa'i, Rasulullah bersabda "Telah dijadikan kesenanganku dalam shalat" (Kamba, 2020).

Menilik dari corak kehidupan tasawuf klasik, para sufi sangat berupaya untuk hanya fokus pada urusan akhirat dan secukupnya saja bersinggungan dengan urusan dunia. Kehidupan sufi pada zaman tasawuf klasik sangat sederhana, dengan pakaian dari bulu domba serta tempat tinggal yang sangat sederhana (Huda, 2017). Namun di zaman kontemporer, fokus pada urusan akhirat memang menjadi tujuan utama terutama oleh para sufi, namun sebagai sufi kontemporer, Buya Kamba mengajak untuk ikut berimplikasi dalam hal-hal kenyataan hidup, dalam artian menyesuaikan dengan situasi dan kondisi saat ini. Seorang sufi kontemporer yang menerapkan konsep mahabah dalam kehidupannya tidak mesti mengenakan pakaian jubah yang melambangkan seorang yang alim, bahkan menjauhkan diri dari kehidupan sosial dan masyarakat. Tasawuf di masa kontemporer ini dapat diterapkan sebagaimana yang dilakukan oleh Buya Kamba, seperti mengenakan pakaian layaknya Muslim pada umumnya, memakai jas untuk acara-acara formal, dan menggunakan mobil sebagai kendaraan. Bahkan implikasi lainnya dapat berbentuk keterlibatan diri dalam organisasi dan pemerintahan dengan tujuan tetap untuk meraih rida-Nya. Mahabbah dalam konteks ini dapat direalisasikan dengan selalu mengingat rahmat yang diberikan oleh-Nya, mensyukuri dan berbagi dengan orang lain yang juga membutuhkan. Hal-hal tersebut telah diterapkan oleh Buya Kamba sejak mendalami tasawuf, terbukti dengan aktifnya beliau di berbagai bidang seperti menuntut ilmu lebih tinggi, menjadi pengajar, sebagai ketua umum berbagai himpunan dan organisasi dan lain sebagainya (Mustofa, 2019). Jika aktivitas sosial dimaknai merupakan anugerah dan bentuk cinta dari Allah, seorang hamba akan 
Jurnal Riset Agama, Volume 1, Nomor 2 (Agustus 2021): 354-364

Hidayatul Fikra/Studi Pustaka Sistematis: Mahabah dalam Tasawuf

Kontemporer Perspektif Buya Nursamad Kamba

melakukannya dengan sungguh-sungguh dan penuh rasa tanggung jawab.

Pandangan Buya Kamba tentang mahabah ini secara eksplisit mengajak pada kehidupan yang bergantung hanya kepada-Nya tanpa mendua. Kehadiran perasaan cinta tersebut harus direfleksikan dalam kehidupan sehari-hari sejak bangun tidur hingga beranjak tidur kembali. Intinya, ajaran yang dibawa oleh Nabi Muhammad harus diinternalisasikan ke dalam diri sebagai bentuk dari perasaan cinta, sehingga manusia dapat mencintai Allah secara merdeka (Fikra, Studium generale, 20 Mei 2019). Itulah sekilas refleksi tasawuf kontemporer Buya Nursamad Kamba.

\section{Kesimpulan}

Mahabbah sebagai puncak dari pengajaran tasawuf pada hakikatnya menjadi sesuatu yang esensial dalam kehidupan umat Islam. Karenanya, perasaan kekosongan dan kehampaan yang disebabkan dengan era modern yang menghargai akal secara berlebihan dapat terselesaikan. Kehadiran Buya Nursamad Kamba, seorang sufi kontemporer yang dalam jejak hidupnya mulai mendalami tasawuf karena sentuhan spiritual yang diajarkan oleh seorang mursyid saat beliau menempuh pendidikan di Universitas Al-Azhar berhasil merubah cara pandangnya terhadap Islam. Pandangannya mengenai cara berislam dengan menanamkan secara kuat perasaan cinta kepada Allah melalui peneladanan akhlak dan kepribadian Nabi Muhammad sebagai manusia yang mulia, serta menjalankan ritual ibadah yang dibawanya membuat konsep mahabah lebih unik dan mudah dipahami oleh orang awam. Konsep mahabah tersebut tidak berbelit-belit dan mampu membuka pikiran bahwa mencintai Allah tidak semestinya sulit dan membuat susah, akan tetapi dapat dilakukan dalam setiap aktivitas kehidupan. Dengan demikian, hasil penelitian ini dinilai sangat relevan dengan kehidupan kontemporer saat ini. Selanjutnya, diharapkan penelitian ini mampu memperkaya khazanah keilmuan di bidang tasawuf, serta secara praktis dapat bermanfaat dalam mengimplementasikan konsep mahabah dalam kehidupan. Diakui bahwa penelitian ini masih terbatas dari segi penelitian terdahulu dan sumber primer terkait tulisan Buya Nursamad Kamba yang mengupas lebih dalam makna dari mahabah dari sudut pandang beliau. Penelitian ini merekomendasikan adanya penelitian lebih lanjut dengan metode kualitatif mengingat Buya Nursamad Kamba merupakan seseorang yang berkiprah lebih luas dalam dunia sosial terutama dalam bidang tasawuf.

\section{Daftar Pustaka}

Ahmad, J. (2018). Desain Penelitian Analisis Isi (Content Analysis). ResearchGate,

June,

$1-20$. 
Jurnal Riset Agama, Volume 1, Nomor 2 (Agustus 2021): 354-364

Hidayatul Fikra/Studi Pustaka Sistematis: Mahabah dalam Tasawuf

Kontemporer Perspektif Buya Nursamad Kamba

https:/ / doi.org/10.13140/RG.2.2.12201.08804

Darmalaksana, W. (2020). Formula Penelitian Pengalaman Kelas Menulis. Jurnal Kelas Menulis UIN Sunan Gunung Djati Bandung. http://digilib.uinsgd.ac.id/32620/

Ferry. (2020). Kajian Teologis dalam Novel "Tuhan Maha Asyik" karya Sujiwo Tejo dan M. Nursamad Kamba. Institut Agama Islam Negeri Kudus.

Hartati. (2018). Mahabbah Perspektif al-Ghazali dan Rabi'ah al-Adawiyah (Studi Komparasi). Universitas Islam Sunan Gunung Djati Bandung.

Haryanto, J. T. (2014). Perkembangan Dakwah Sufistik Perspektif Tasawuf Kontemporer. Addiin, 8(2), 269-294.

Hasnawati, H. (2015). Faham Mahabbah dan Ma'rifah dalam Tasauf Islam. Al-Qalb: Jurnal Psikologi Islam, 6(2), 100-108.

Hisnuddin. (2020). Pendidikan Cinta Kasih Perspektif Jalaluddin Rumi. Universitas islam Negeri Syarif Hidayatullah Jakarta.

Huda, S. (2017). Karakter Historis Sufisme pada Masa Klasik, Modern, dan Kontemporer. Teosofi: Jurnal Tasawuf Dan Pemikiran Islam, 7(1), 186215. https://doi.org/10.15642/ teosofi.2017.7.1.184-215

Irham, M. I. (2012). Membangun Moral bangsa Melalui Akhlak Tasawuf (T. R. Soraya (ed.); 2nd ed.). Pustaka Al-Ihsan.

Kamba, M. N. (2018). Kids Zaman Now: Menemukan Kembali Islam. Pustaka IMaN.

Kamba, M. N. (2020). Mencintai Allah Secara Merdeka: Buku Saku Tasawuf Praktis Perjalanan Maiyah (T. Pram (ed.); I). Pustaka IIMaN.

Kumalla, A. (2019). Konsep Mahabbah (Cinta) dalam "Rubaiyat" Karya Rumi dan Relevansinya dalam Pendidikan Agama Islam. Universitas Islam Negeri Raden Intan Lampung.

Mustofa, H. (2019). Tarekat "Virtual": Sebuah Gagasan Alternatif Bertarekat dari Muhammad Nursamad Kamba. Jurnal Kajian Islam Intradisipliner, 4(2), 163-186.

Pratiwi, N., \& Liliani, E. (2021). Perspectives on The Monopoly of Religiusity in Novel Tuhan Maha Asyik 2 By Sujiwo Tejo and Dr. Muhammad Nursamad Kamba. International Journal of Linguistics, Literature and Translation, 4(6), 267-279. https:/ / doi.org/10.32996/ijllt

Rahman, M. D. (2019). Pesan dakwah Majelis Maiyah Bangbangwetan di Kota Surabaya. Universitas Islam Negeri Sunan Ampel Surabaya.

Saputra, A. (2019). Konsep Mahabbah (Cinta) dalam Pemikiran Syekh Zulfigar Ahmad. Universitas Islam Negeri Syarif Hidayatullah Jakarta.

Wasalmi. (2014). Mahabbah dalam Tasawuf Rabi'ah Al-Adawiah. Jurnal Sulesana, 9(2), 81-87.

Wati, M. (2014). Konsep Mahabbah dan Ma'rifah dalam tasawuf Dzunnun alMishri. UIN Sunan Kalijaga Yogyakarta. 
Jurnal Riset Agama, Volume 1, Nomor 2 (Agustus 2021): 354-364

Hidayatul Fikra/Studi Pustaka Sistematis: Mahabah dalam Tasawuf Kontemporer Perspektif Buya Nursamad Kamba 